\title{
Estimation of the Active Social Network of Street Children in Shiraz (A City of Iran)
}

\author{
Nasrin Motazedian (iD ${ }^{1}$, Mehrab Sayadi (iD ${ }^{2,}{ }^{*}$, Somaye Oboodi ${ }^{3}$ and Hassan Joulaei (iD ${ }^{4}$ \\ ${ }^{1}$ Shiraz Transplant Research Center, Shiraz University of Medical Sciences, Shiraz, IR Iran \\ ${ }^{2}$ Cardiovascular Research Center, Shiraz University of Medical Sciences, Shiraz, IR Iran \\ ${ }^{3}$ Registration Office of Fars Province, Shiraz, IR Iran \\ ${ }^{4}$ Shiraz HIV|AIDS Research Center, Institute of Health, Shiraz University of Medical Sciences, Shiraz, IR Iran \\ "Corresponding author: Cardiovascular Research Center, Shiraz University of Medical Sciences, Shiraz, IR Iran. Email: sayadi_me@yahoo.com
}

Received 2019 June 12; Revised 2020 April 22; Accepted 2020 May 04.

\begin{abstract}
Street children are a hard-to-reach population. Since the direct method is not feasible and has some limitations, we utilized the network scale-up (NSU) as an indirect method. This study was conducted in Shiraz municipalities. Our target population was Iranian boys between 10 to 18 years of age during the years 2014 to 2016. Three trained psychologists conducted face to face interviews with 86 street children (boys) on the streets, through the convenience sampling technique. The social network size of street boys in Shiraz was estimated at 17 persons (ranging from zero to 92 people, mean $=17 \pm 17$, median $=13$ ). Overall, the network size of the hidden population might be smaller than the general population, due to the stigmatized nature of their behavior and place of work.
\end{abstract}

Keywords: Homeless Youth (Street Children), Network Scale-up, Iran, Shiraz

\section{Background}

Size estimation of a hard-to-reach population is one of the main issues in the social science and public health domain (1). Since the direct method is not feasible and has some limitations, an indirect method was developed to overcome these issues. One indirect method is network scale-up (NSU), and a social network size estimation is the first step in this method $(2,3)$. The NSU method shows how people in a network of subgroups have a direct link with the real size of that subgroup in a general population (4). Street children are a subgroup of the hard-to-reach population. They are highly prone to high-risk behaviors and their consequences (5). Several studies were conducted on Iranian general population to estimate active social network size $(2,3)$. One study was conducted to estimate the population size of two HIV/AIDS key populations; injecting drug users and female sex workers in Iran (1). So far, no study has estimated the population size of street children in Iran; hence, we decided to estimate the size of street children's social networks in Shiraz.

\section{Patients and Methods}

This cross-sectional study was conducted in 6 different districts of Shiraz municipalities, located in southwestern
Iran. Our target population was Iranian boys between 10 18 years of age who worked in the street 2014 - 2016. Three trained psychologists conducted face to face interviews with 86 street children (boys) on the streets, through the convenience sampling technique. The researchers asked the target group how many people were recognized in a specific subpopulation inside the community to approximate social network size in the indirect method. In case the participants knew somebody in the mentioned subpopulation by name and face and could visit, call or email the cited person whenever he/she wanted, and vice versa, we found that they knew each other. They had contact by phone, email, or in person at least once within the past two years $(2,4)$.

We obtained their total population by referring to the Registrar-General of Fars province. Approximately, 86,426 boys' names were obtained, and their birth certificate was from the city of Shiraz. Names were selected based on the guidelines provided in the literature: proportion in the general population being from $0.1 \%$ to $4 \%$, popularity not being changed in recent decades, and genderneutral/ambiguous names (3). The information collection form was about the number of individuals called (Ali and Ali Reza, Reza, Mehdi, Amir Hossein). In this method, we asked how many boys he knew by name (4). The basic equa- 
tion in the NSU method is $\mathrm{e} / \mathrm{t}=\mathrm{m} / \mathrm{C}$. In this equation, $\mathrm{e}$ is the size of a specific reference group, and $t$ is the size of the total population, which both of them obtained from other sources. $M$ is the number of individuals that each respondent knows from a specific reference group, and $\mathrm{C}$ is the respondent's network size" $(3,6)$. First, we need to estimate $\mathrm{C}$ as the network size for this population. $\mathrm{C}$ is different in each community and depends on its social and cultural structure (4). If multiple names were used, like our study, the social network size was estimated through the following equation:

$c_{i}=\frac{\left(t \times \sum m_{i j}\right)}{e_{j}}$

The $\mathrm{m}$ is the average number of individuals belonging to a sub-population that is known by our samples. The standard error of estimator was obtained from the following formula:

$S E=\operatorname{sqrt}\left(\frac{\left(t \times c_{i}\right)}{e_{j}}\right)$

We used to mean as maximum likelihood estimation for estimating the final size of population $(2,7)$.

Statistical analysis was performed using Statistical Package for Social Sciences (SPSS for Windows, version 16.0. Chicago, SPSS Inc.).

\section{Results and Discussion}

Our study approach was through the frequency of these names. A total of 86 street boys were interviewed in Shiraz with a mean \pm standard deviation (SD) age of $\mathbf{1 5 . 4 2}$ \pm 2.15 years. The number of children in a family ranged from three to twelve, with a mean \pm SD of $5.14 \pm 1.5$ children. Working hours in a day were from two to sixteen, with a mean \pm SD of $7.34 \pm 2.19$ hours. A total of $39.8 \%$ were studying at the elementary level. The length of their stay in the street was one to 132 weeks. The name frequency of Ali and Ali Reza ranged from zero to ten times. Also, the name frequency of the Reza was zero to four, Mehdi zero to five, and Amir Hossein zero to three times. According to the mentioned formula and using the MLE method, the social network size of street boys in Shiraz was estimated at 17 persons (ranging from zero to 92 people, mean $=17 \pm 17$, and median $=13$ ).

The methods such as census/enumeration, nomination, population surveys, mathematical, multiplier, capture-recapture, respondent-driven sampling (RDS), and network scale-up are considered as direct and indirect methods for size estimation. In direct PSE, we need direct contact with members of the hidden group, but in indirect
PSE no direct contact with members of the hard-to-reach group is required (8). Iran's national HIV strategy plan for 2015 - 2020 takes into account street children as one of the key populations in contracting and transmitting HIV (9). Also, studies reported weak social ties, networks, and lack of supports among street children, because of unsteady working place or fear of society $(10,11)$. In the current study, we used an indirect method called network scale-up. Having the network size as the basic information can be used in future studies. Therefore, we estimated the social network size in children to be used in future studies.

The active network size of the Iranian population was estimated at 239 (4). A study estimated the social network size of Tehran province residents to be 259.1 (95\%CI: 242.2, 276) (2). Two studies conducted in Kerman on the estimation of the active social network size of Kermani women and men showed that on average, each woman knew about 234 people, and each man knew 303 people (age range of 18 - 45 years) in Kerman $(3,12)$.

Recently, Vameghi and colleagues published a result of mapping and estimating the population size of street children in Bandar Abbas, Zahedan, Kermanshah, Karaj, Mashhad, and Tehran. In aggregate for the six cities, the number of street children was estimated at 5296, and the total number for street children in Iran was estimated at 26,000 children (13). In our study, the social network size of street boys in Shiraz was estimated at 17 persons (ranging from zero to 92 ).

The mean size of the social network of the "on" the street children in Kenyan towns (especially Eldoret town) was 10.92 (SD = 3.46), "of" the street 11.70 (SD = 3.91), shelter children $17.60(S D=3.99)(12)$. Social networks of street children in Ibadan, Nigeria, was estimated at 25 (14). The social network size of shelter children in Eldoret town was similar to the "on" the street children in Shiraz. But the social network size of the "on" the street children in Eldoret, Ibadan, and Shiraz was different. The size of the social network varies and depends on education and district of residence (15).

A study was conducted to estimate the social network of two key groups of HIV/AIDS in Shiraz and Kerman. The results showed injecting drug users, and female sex workers knew an average number of 15.92 , and 17.31 persons (1). The network size of the hidden population might be smaller than the general population, due to the stigmatized nature of their behavior and place of work (1). Social network size estimation is the first step in the network scale-up method to calculate the hard-to-reach population for the allocation of financial and human resources as well as treatment and prevention program implementation. 


\section{Acknowledgments}

The authors would like to thank of Vice-Chancellor of Research and Technology (Grant no. 94-01-59-9460).

\section{Footnotes}

Authors' Contribution: Study concept and design: Nasrin Motazedian and Mehrab Sayadi; analysis and interpretation of data: Nasrin Motazedian, and Mehrab Sayadi; drafting of the manuscript: Nasrin Motazedian; critical revision of the manuscript for important intellectual content: Nasrin Motazedian, Mehrab Sayadi, Somaye Oboodi, and Hassan Joulaei; statistical analysis: Mehrab Sayadi.

Conflict of Interests: The authors declare that they have no conflict of interest regarding the publication of this paper.

Ethical Approval: This study was approved by the Ethics Committee of Shiraz University of Medical Sciences (IR.SUMS.REC.1394.S727).

Funding/Support: This study was supported by Shiraz University of Medical Sciences. Shiraz, Iran.

\section{References}

1. Maghsoudi A, Baneshi MR, Neydavoodi M, Haghdoost A. Network scale-up correction factors for population size estimation of people who inject drugs and female sex workers in Iran. PloS one. 2014;9(11). e110917.

2. Shati M, Haghdoost A, Majdzadeh R, Mohammad K, Mortazavi S. Social network size estimation and determinants in tehran province residents. Iranian journal of public health. 2014;43(8):1079.

3. Zamanian M, Baneshi MR, Haghdoost AA, Mokhtari-Sorkhani T, Amiri F, Zolala F. Estimating the Size and Age-gender Distribution of Women's Active Social Networks. Addict Health. 2016;8(3):170-8. [PubMed: 28496955]. [PubMed Central: PMC5422013].
4. Rastegari A, Haji-Maghsoudi S, Haghdoost A, Shatti M, Tarjoman T, Baneshi MR. The estimation of active social network size of the Iranian population. Global journal of health science. 2013;5(4):217.

5. Pullum T, Cappa C, Orlando J, Dank M, Gunn S, Mendenhall M, et al. Systems and strategies for identifying and enumerating children outside of family care. Child Abuse \& Neglect. 2012;36(10):701-10. doi: 10.1016/j.chiabu.2012.09.003.

6. Kadushin C, Killworth PD, Bernard HR, Beveridge AA, Scale-Up methods as applied to estimates of heroin use. Scale-Up methods as applied to estimates of heroin use. J Drug Issues. 2006;36(2):417-40.

7. McCormick TH, Salganik MJ, Zheng T. How many people do you know?: Efficiently estimating personal network size. J Am Stat Assoc. 2010;105(489):59-70.

8. Kazerooni PA, Motazedian N, Motamedifar M, Sayadi M, Sabet M, Lari MA, et al. The prevalence of human immunodeficiency virus and sexually transmitted infections among female sex workers in Shiraz, South of Iran: by respondent-driven sampling. International journal of STD \& AIDS. 2014;25(2):155-61.

9. Ansari H, Moghaddam AA, Mohammadi M, Arbabisarjou A. Predictors of high-risk behaviors among street children in Zahedan, Southeastern Iran. International Journal of High Risk Behaviors and Addiction. 2016;5(4)

10. Hai MA. Problems faced by the street children: A study on some selected places in Dhaka City, Bangladesh. International Journal of Scientific \& Technology Research. 2014;3(10):45-56.

11. Ayuku D. Family networks of street children and school children of Eldoret, Kenya. East African Journal of Public Health. 2005;2(1).

12. Shokoohi M, Baneshi MR, Haghdoost AA. Estimation of the active network size of kermanian males. Addict Health. 2010;2(3-4):81-8. [PubMed: 24494105]. [PubMed Central: PMC3905511].

13. Vameghi M, Roshanfekr P, Ali D, Noroozi M, Madani S, McFarland W, et al. Population Size Estimates of Street Children in Iran: Synthesis of Multiple Methods. Journal of Urban Health. 2019:1-9.

14. Omiyinka FO. Social networks and livelihood of street children in Ibadan, Nigeria. International Journal of Sociology and Anthropology. 2009;1(5):82-9.

15. Guo W, Bao S, Lin W, Wu G, Zhang W, Hladik W, et al. Estimating the size of HIV key affected populations in Chongqing, China, using the network scale-up method. PloS one. 2013;8(8). e71796. 